\title{
RATIONALIZATION AND OPTIMIZATION OF HEMODIALYSIS PROCEDURE-III*
}

\author{
J. DE BOER and R. H. STINSON \\ Department of Biomedical Sciences and Department of Physics, University of Guelph, Guelph, Ontario, \\ Canada
}

\begin{abstract}
For single-pass counterfiow dialysers, an equation has been derived which incorporates flow rates in blood and dialysate compartments, blood volume, overall diffusion coefficient of the substance involved and geometrical membrane properties. To verify the theory effects of flow in the blood and dialysate compartments, on mass transfer of sodium through the membranes in a Kiil dialyser were studied in in vitro experiments, using water/water and blood/ dialysate systems. The geometrical properties of the membranes and the overall diffusion coefficient of sodium were determined. The latter was less in the blood/dialysate system than in the water/water system. The efficiency of this dialyser was expressed as a clearance. The flow dependency of the clearance appeared to be asymptotic as demonstrated empirically by many investigators. Actual experimental points followed the theoretical curves and verified the theory. The theory has to be extended to cope with in vivo experiments.
\end{abstract}

\section{NOTATION}

$Q_{1} \mathrm{~cm}^{3} \mathrm{~s}^{-1}$

$Q_{2} \mathrm{~cm}^{3} \mathrm{~s}^{-1}$

flow in blood compartment

flow in dialysate compartment

$C_{10}$ moles $\mathrm{cm}^{-3}$ initial blood concentration of the substance to be removed

$C_{1}$ moles $\mathrm{cm}^{-3}$ blood concentration of substance to be removed at point of inlet to the dialyser at any time $t$

$\Delta x \mathrm{~cm}$

$S \mathrm{~cm}^{2}$

$D \mathrm{~cm}^{2} \mathrm{~s}^{-1}$

effective thickness of membrane effective surface area of membrane overall diffusion coefficient of substance to be removed through the triple laminate composed of stationary fluid film on the blood side, wet membrane and stationary fluid film on the dialysate side

$V_{1} \mathrm{~cm}^{3}$ total volume of the blood compartment.

\section{INTRODUCTION}

IN A PREvious investigation current single-pass, counterflow dialysers were mathematically analysed (STINSON and DE BOER, 1970). This analysis yields a new equation involving all parameters which influence mass transfer through the membranes in these dialysers assuming a constant temperature and the absence of ultrafiltration and osmosis. The equation predicts that the concentration in the blood compartment at any time $t$ is given by

where

$$
C_{1}=C_{1_{0}} \mathrm{e}^{-B t}
$$

$$
\begin{gathered}
B=\frac{2 D^{\prime} Q_{1} Q_{2}}{V_{1}\left(D^{\prime} Q_{1}+D^{\prime} Q_{2}+2 Q_{1} Q_{2}\right)} \\
\text { and } D^{\prime}=\frac{D S}{\Delta x}
\end{gathered}
$$

As has been discussed, the clearance will be the product of the blood volume $V_{1}$ and the value of $B$. To verify this theory, the effects of flow in the blood and dialysate compartments on the mass transfer of sodium through the membranes in a standard single-pass Kiil dialyser were studied in in vitro experiments. To eliminate as many variables as possible, distilled water was used in both compartments of the dialyser in the first instance. Once the theory was verified blood was used in the blood compartment and an isotonic dialysate in the dialysate compartment. To obtain concentration values of a high

* Received 22 June 1971. 
accuracy, labelled sodium was used in the water/ water as well as in the blood/dialysate experiments. From the concentration (=radioactivity) vs. time curves the $B$ values could be determined. Measurements of the effective surface area and thickness of the membrane were made. Since $Q_{1}, Q_{2}$, and $V_{1}$ were known, the overall diffusion constant $D$ for sodium could then be calculated for both water/water and blood/ dialysate systems. No attempt was made to evaluate separately the contributions of the various layers in the diffusion barrier. The purpose was to obtain an integrated effect across the triple-laminate of the membrane and the fluid layer adjacent to each side. In the blood/dialysate system citrated dog blood of 41 per cent haematocrit was used to avoid the permeability inconsistencies pointed out by GAYLOR et al. (1970). Therefore $D$ in a water/water or blood/dialysate depends only on the characteristics of the membrane involved. Clearance, which incorporates $D$, however, depends upon the design of the dialyser used as discussed previously (STINSON and DE BOER, 1970). This approach does not include the possibility of concurrent metabolic production or the presence of other compartments. Concurrent metabolic production has been incorporated into similar equations (DE BOER et al., 1966; STINSON and DE BOER, 1970). The inclusion of additional compartments will be considered in the next article in this series. (de Boer and Stinson). Most theoretical approaches to hemodialysis (reviewed by CoLton, 1967) have been either fragmentary or related to models other than the Kiil while the variables used have frequently been difficult to handle.

\section{MATERIAL AND METHODS}

A standard Kiil dialyser and console (Sweden) were used in these experiments. Pressures were manometrically recorded at the inlet and outlet of the blood and dialysate compartment. Both compartments were either primed with distilled water or with dog blood and dialysate, and kept at a constant temperature of $37^{\circ} \mathrm{C}$. The total volume, including the volume inside the dialyser, of the blood compartment never exceeded
$1000 \mathrm{~cm}^{3}$. The fluid in the blood compartment was recirculated with the aid of a roller pump with a variable speed. The pump in the console was used to pump the water or the dialysate from a reservoir through the dialyser into a drain.

In order to avoid flow measurements during the experiments, pressure-flow curves in water/ water and blood/dialysate systems were obtained previously. This was achieved by measuring with a calibrated cylinder the outflow per unit time for different pump speeds. Simultaneously the pressures at the inlets and outlets of both compartments were recorded. When a pressure-flow curve was being obtained for one compartment the flow rate in the other compartment was kept constant. During the experiments the pressure could be determined and the corresponding flow could be read from the graph.

In the water/water experiments $6 \mathrm{~g}$ of labelled sodium carbonate was introduced into the blood compartment at time zero, and a corresponding amount of unlabelled sodium carbonate into the dialysate reservoir. The fluids in both compartments were therefore iso-osmotic. Moreover this condition was checked with an osmometer (Advanced Instruments Inc). Since the dialysate was pumped from a reservoir through the unit and on into a drain, the actual volume of dialysate was not important. Quantities ranging from 20 to 501 . were used.

Citrated dog blood 41 per cent haematocrit approximately was used in the blood/dialysate experiments. For the dialysate a solution containing the electrolyte composition of the extracellular fluid of the normal dog was used (SKEGGS et al., 1949). When $6 \mathrm{~g}$ of labelled sodium carbonate was added to 11 . of whole blood and $8 \mathrm{~g}$ of unlabelled sodium carbonate per litre was added to the dialysate the two fluids had osmolarities equal to within 2 per cent.

The ${ }^{24} \mathrm{Na}$ was produced by placing sodium carbonate samples in a neutron source with a flux of $3 \times 10^{7}$ neutrons $\mathrm{s}^{-1} \mathrm{~cm}^{-2}$ for periods of $18-24 \mathrm{~h}$. A shielded sodium iodide scintillation detector measured the total activity in the blood compartment. In each of three water/water 
experiments the decrease of total activity in the blood compartment was measured using four different flow rates in the blood compartment for $9 \mathrm{~min}$ each. Two flow rates were selected in the laminar part of the pressure-flow curve and two in the turbulent part of the curve. The flow of the dialysate was kept at a constant rate of $16 \cdot \dot{6} \mathrm{~cm}^{3} \mathrm{~s}^{-1}$. The same experiment was performed using a constant flow-rate in the blood compartment of $4 \mathrm{~cm}^{3} \mathrm{~s}^{-1}$ and three different flow rates in the dialysate compartment; one in the laminar part and two in the turbulent part of the curve. Similar blood/dialysate experiments were performed at a dialysate flow rate of $13 \cdot \dot{3} \mathrm{~cm}^{3} \mathrm{~s}^{-1}$. Background readings of radioactivity were taken at the beginning of each experiment and subtracted from the total activity during the experiment.

The mean thickness of a wet membrane (Cuprophane PT 150) was determined by folding a wet membrane four times and measuring the thickness of the folded membrane on randomized spots using a micrometer.

By injecting an aniline blue solution (aniline blue does not stain the membrane nor the tubing nor does it permeate the membranes) into the different compartments, the flow pattern could be observed with the aid of fluorescent bulbs placed underneath the dialyser. An approximation of the effective surface of the membranes could thus be calculated.

Since electrolytes were being used, the possibility of creating potential differences across the membranes existed. Platinum electrodes and a potentiometer were used to measure such potentials.

\section{RESULTS}

Figure 1 provides the information required to calculate the area $S$. The dye patterns indicate that the small triangular areas in the corners and the narrow strip down the centre are ineffective. Since there are four layers of cellophane involved, the total area then will be $4[88 \times 29 \cdot 5-4(1 / 2$ $\times 6 \times 2$ )] or $1.029 \mathrm{~m}^{2}$.

The mean thickness of the wet cellophane
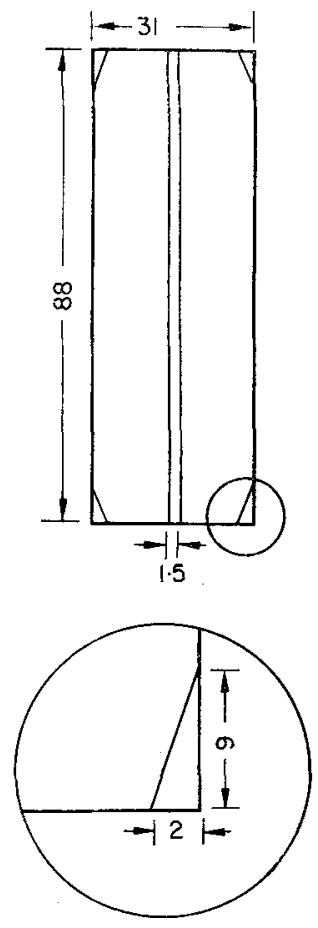

Fig. 1. Schematic diagram of the effective surface area of the membrane used in a Kiil dialyser. For calculations see text.

membrane was $2.5 \times 10^{-3} \mathrm{~cm}(S D=0.1 \times$ $10^{-3} \mathrm{~cm} ; n=10$ ).

Figure 2 represents the pressure-flow curves in the blood as well as in the dialysate compartment of the dialyser for water/water and blood/ dialysate systems. Each pressure-flow curve represents the pooled data from three experiments which yielded identical results.

Keeping either $Q_{1}$ or $Q_{2}$ constant and using variable values for $Q_{2}$ and $Q_{1}$, respectively, a maximum pressure difference across the membrane was measured of about $40 \mathrm{~cm} \mathrm{H}_{2} \mathrm{O}$ (see Fig. 2). Due to this, some ultrafiltration from the blood to the dialysate compartment took place. By measuring $V_{1}$ at the end of each series of experiments a maximum decrease of $35 \mathrm{~cm}^{3}$ or 3.5 per cent of the total volume in the blood compartment was found. In each experiment, however, ultrafiltration for each of the different flow rates used was correspondingly lower. 


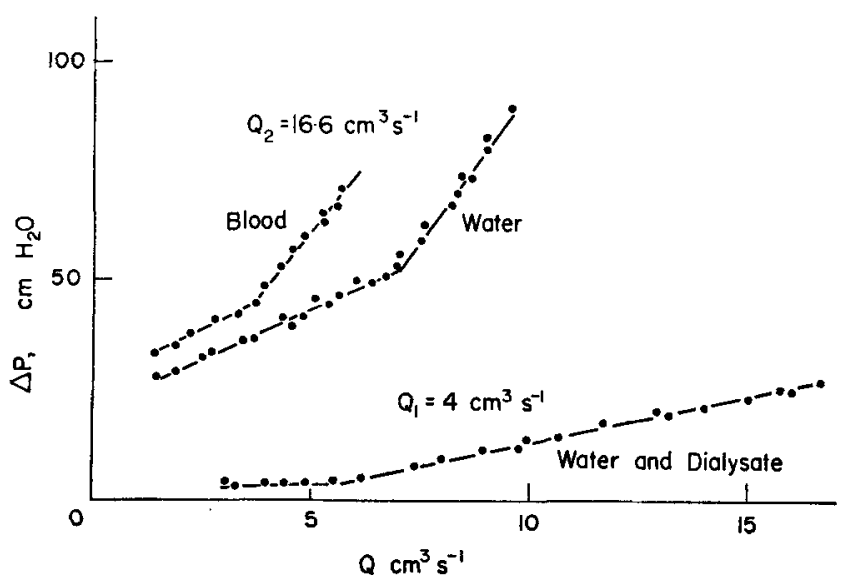

Fig. 2. Pressure-flow curves of water and blood in the blood compartment (upper two curves) using a constant $Q_{2}$, and of water and dialysate in the dialysate compartment (lower curve) using a constant $Q_{1}$.

Errors due to the natural decay of ${ }^{24} \mathrm{Na}$ were also negligible because the half-life of ${ }^{24} \mathrm{Na}$ is $14.8 \mathrm{~h}$, while the radioactivity for each flow rate was measured over a 9 -min period, viz. a 1 per cent error for each of the flow rates used.

Figure 3 is a typical semi-logarithmic graph of radioactivity (concentration) vs. time in

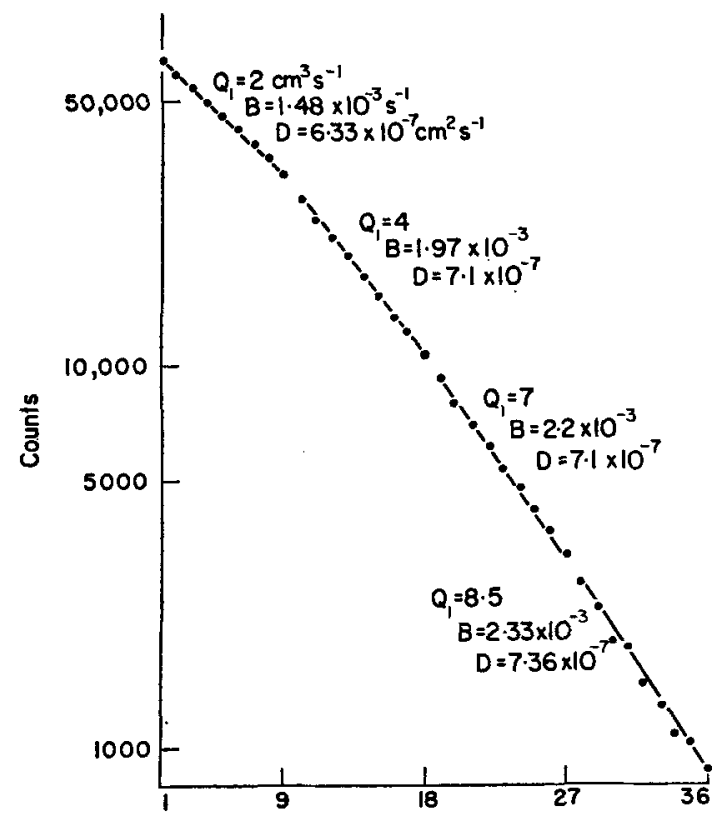

FIG. 3. Semi-log graph of radioactivity (=concentration) versus time in a water/water experiment. Similar graphs were obtained in blood/dialysate experiments. a water/water experiment. The flow in the dialysate compartment was maintained at $16 \cdot \dot{6} \mathrm{~cm}^{3}$ $\mathrm{s}^{-1}$ while four different flow rates in the blood compartment were used. The $B$ values are the slopes of the regression lines obtained by a least square fit. Coefficients of correlation ranged from 0.992 to 0.999 with $8 \mathrm{deg}$ of freedom. Similar graphs were obtained in the blood/ dialysate experiments.

A potential difference of about $100 \mathrm{mV}$ was measured across the membrane, the blood side being negative with respect to the dialysate.

In 12 separate determinations of the overall diffusion coefficient for sodium in the water/ water system an average value of $6.3 \times 10^{-7} \mathrm{~cm}^{2}$ $\mathrm{s}^{-1}$ was obtained with a standard deviation of $1.6 \times 10^{-7} \mathrm{~cm}^{2} \mathrm{~s}^{-1}$. The overall diffusion coefficient for sodium in a blood/dialysate system was $2.0 \times 10^{-7} \mathrm{~cm}^{2} \mathrm{~s}^{-1}$ with a standard deviation of $0.2 \times 10^{-7} \mathrm{~cm}^{2} \mathrm{~s}^{-1}$ for 7 separate determinations. No correlation could be found between the separate determinations of $D$ and the corresponding flow rates used. The majority of the variation in $D$ values for each of the systems used occurred between, rather than within, experiments, as can be seen in Table 1. For each experiment an average value of $D$ can be calculated and a theoretical curve of $B$ vs. flow can be plotted. 
Table 1. Results of calculations of $B, D^{\prime}$ and $D$ values for several flow rates of water in four different experiments

\begin{tabular}{ccccc}
\hline \multicolumn{5}{c}{$Q_{2}$ Constant at $16.6 \mathrm{~cm}^{3} \mathrm{~s}^{-1}$} \\
\hline Exp. & $\begin{array}{c}Q_{1} \\
\left(\mathrm{~cm}^{3} \mathrm{~s}^{-1}\right)\end{array}$ & $\begin{array}{c}B \times 10^{3} \\
\left(\mathrm{~s}^{-1}\right)\end{array}$ & $\begin{array}{c}D^{\prime} \\
\left(\mathrm{cm}^{3} \mathrm{~s}^{-1}\right)\end{array}$ & $\begin{array}{c}D \times 10^{7} \\
\left(\mathrm{~cm}^{2} \mathrm{~s}^{-1}\right)\end{array}$ \\
\hline 1 & 2 & 1.57 & 3.65 & 7.00 \\
1 & 5 & 2.03 & 2.66 & 6.65 \\
1 & 7.5 & 2.07 & 2.60 & 6.51 \\
1 & 9 & 2.21 & 2.73 & 6.82 \\
\hline 2 & 2 & 1.25 & 1.92 & 4.81 \\
2 & 4 & 1.72 & 2.35 & 5.87 \\
2 & 6.5 & 1.75 & 2.16 & 5.40 \\
2 & 8.5 & 1.84 & 2.20 & 5.50 \\
\hline 3 & 2 & 1.48 & 2.53 & 6.33 \\
3 & 4 & 1.97 & 2.84 & 7.10 \\
3 & 7 & 2.20 & 2.84 & 7.10 \\
3 & 8.5 & 2.33 & 2.94 & 7.36 \\
\hline
\end{tabular}

\begin{tabular}{ccccc}
\hline \multicolumn{5}{c}{$Q_{1}$ constant at $4 \cdot 0 \mathrm{~cm}^{3} \mathrm{~s}^{-1}$} \\
\hline \multicolumn{5}{c}{$\left(\begin{array}{l}Q_{2} \\
\left(\mathrm{~cm}^{3} \mathrm{~s}^{-1}\right)\end{array}\right.$} \\
\hline 4 & 16 & $1 \cdot 72$ & $2 \cdot 35$ & $5 \cdot 87$ \\
4 & 8 & 1.43 & $2 \cdot 69$ & $6 \cdot 73$ \\
4 & 4 & $1 \cdot 33$ & $2 \cdot 00$ & $5 \cdot 00$ \\
\hline
\end{tabular}

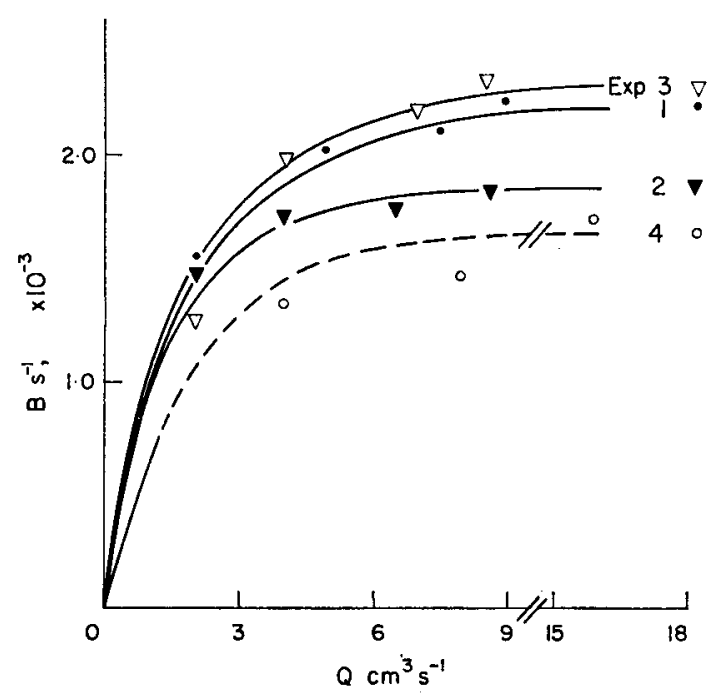

FIG. 4. Theoretical curves $B$ vs. $Q_{1}$ and $Q_{2}$. Solid lines represent three separate water/water experiments for a constant $Q_{2}=16 . \dot{6} \mathrm{~cm}^{3} \mathrm{~s}^{-1}$. The broken line is for a constant $Q_{1}=4 \mathrm{~cm}^{3} \mathrm{~s}^{-1}$.
In Fig. 4 it is seen that asymptotic values of $B$ for the water/water experiments are approached as one flow rate increases, while the other is held constant. When $B$ values are multiplied by $V_{1}$ the same asymptotic curves are obtained for clearance vs. flow. The actual experimental points for each experiment follow closely the trends indicated by the theoretical lines. If the graph is drawn based on the overall average $D$, somewhat more scatter is observed due to variations between the experiments.

Table 2 and Fig. 5 present similar data for 7 blood/dialysate experiments in which the dialysate flow was held at $13 \cdot \dot{3} \mathrm{~cm}^{3} \mathrm{~s}^{-1}$.

Table 2. Measured $B$ values and calculated $D^{\prime}$ values for a series of blood/dialysate experiments with $Q_{2}$ constant at $13 \cdot 3 \mathrm{~cm}^{3} \mathrm{~s}^{-1}$ and total blood volume of $500 \mathrm{~cm}^{3}$

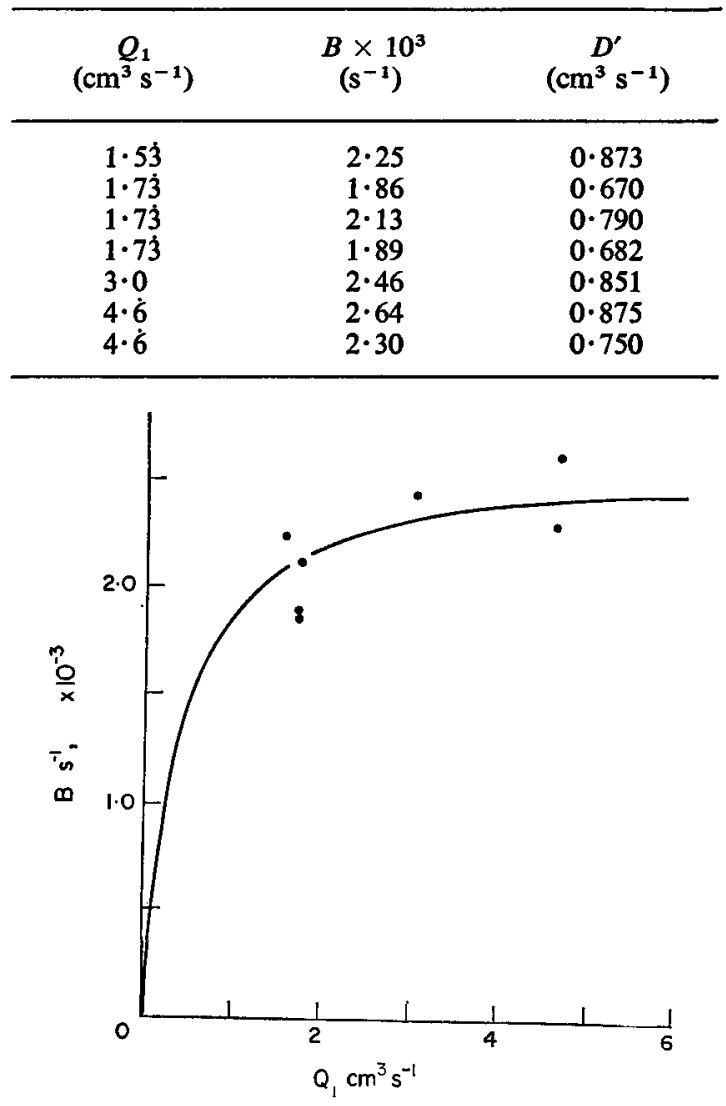

FIG. 5. Theoretical curve of $B$ vs. $Q_{1}$ in blood/dialysate experiments. $Q_{2}$ constant at $13 \cdot 3 \mathrm{~cm}^{3} \mathrm{~s}^{-1}$. Seven experimental points are shown. 


\section{DISCUSSION}

The pressure-flow curves for the different experiments were highly reproducible and showed a change of slope within the flow limits used. This is usually interpreted as a transition from laminar to turbulent flow. Because of the higher viscosity value of blood the curve for blood is moved upward and more to the left, and as a result turbulent flow will occur at a lower flow rate. Due to irregularities and therefore uncertainties the Reynold's numbers could not be calculated. Another characteristic can be observed in Fig. 2: the pressure-flow curves for the blood compartment extrapolate to an initial pressure difference of about $20 \mathrm{~cm} \mathrm{H}_{2} \mathrm{O}$. This can be interpreted as analogous to the opening pressure of collapsed lung alveoli or the opening pressure of a collapsed vessel, as the pressure needed to separate the two non-rigid membranes. Because the dialysate compartment is rigid this phenomenon is not observed and the curve extrapolates to zero flow at zero $\Delta P$.

While the rate of removal of labelled sodium was dependent on the magnitude of the flow, it was not altered by the transition from laminar to turbulent flow. It appeared that mixing is sufficient in laminar flow and that no beneficial effects can be expected from turbulent flow, within the flow ranges normally used.

Errors due to ultrafiltration of less than 2 per cent for each of the flow rates used were measured. Even during the 9-min period in which the highest flow rate was used ultrafiltration did not exceed $10-20 \mathrm{ml}$ or 1 to 2 per cent of the total volume. These small ultrafiltration effects are in agreement with those reported by MACEY and Wolf (1960).

Multiple folding of the wet cellophane membrane permitted the accurate measurement of the thickness of this membrane. It also showed an almost twofold increase in thickness of the swollen membrane compared to the dry one, which is in agreement with the findings of LYMAN (1963).

The measurements of the effective surface area were less accurate and therefore only an approximation could be made. Moreover the effective surface area may vary with the flow rate used, although this could not be detected by observing the flow patterns.

The use of a labelled substance permitted accurate measurements of the concentration at frequent time intervals and this in turn provided accurate $B$ values. The choice of using labelled sodium was governed by economic and practical considerations (counting is simple and results therefore more precise for the energetic sodium gamma peak).

Although the pores in the dog erythrocytes are large (VILLEGAS et al., 1959) and sodium exchange across the membrane somewhat faster than in many other species (LANGE et al., 1970) this exchange, however, is sufficiently slow that there would be a negligible movement of labelled sodium across the membrane within the brief duration of our experiments. Therefore it was assumed that the labelled sodium remained entirely within the plasma and the $V_{1}$ used in the calculations was the plasma volume of the citrated dog blood used with an average haematocrit of 41 per cent.

With the determined $B$ and $V_{1}$ values and the measurements for the effective surface area and thickness of the membrane the overall diffusion coefficients for sodium in water/water and blood/ dialysate systems could be calculated. A surprising variety of $D$ values for simple sodium compounds, e.g. $\mathrm{NaCl}$, exist in the literature, varying from as high as $2 \times 10^{-5} \mathrm{~cm}^{2} \mathrm{~s}^{-1}$ (BABB et al., 1968; PAPPENHEIMER et al., 1951) to as low as $1 \times$ $10^{-5} \mathrm{~cm}^{2} \mathrm{~s}^{-1}$. The Handbook of Chemistry and Physics (49th edition) gives $1.5 \times 10^{-5} \mathrm{~cm}^{2} \mathrm{~s}^{-1}$, at $25^{\circ} \mathrm{C}$ which should adjust to 1.56 at $37^{\circ} \mathrm{C}$. This value was chosen for our comparison. WILcox et al. (1960) give the fractional pore area of cuprophane membrane as 0.05 and $D$ in a water/ water system would therefore be 5 per cent of that in water only, e.g. $7.8 \times 10^{-7} \mathrm{~cm}^{2} \mathrm{~s}^{-1}$, which is reasonably close to our observed value of $6.3 \times 10^{-7} \mathrm{~cm}^{2} \mathrm{~s}^{-1}$. On the assumption that the $V_{1}$ used was the plasma volume the $D$ value in the blood/dialysate system was calculated to be $2 \times 10^{-7} \mathrm{~cm}^{2} \mathrm{~s}^{-1}$. If one goes to the other extreme and assumes that $V_{1}$ should be 
the entire blood volume then the $D$ value would increase to $4.1 \times 10^{-7} \mathrm{~cm}^{2} \mathrm{~s}^{-1}$ which is still markedly less than in the water/ water system. A number of factors combine to explain this significant difference. In a blood/dialysate system the measured negative $100 \mathrm{mV}$ potential on the blood side would exert a considerable retarding force on the sodium ions and cause a corresponding decrease in diffusivity. SwEENEY and GALLETTI (1964) have cautioned that "solute diffusion responds to electrochemical concentration gradients, including the Donnan equilibrium effect of plasma proteinate ions". RENKIN (1956) has warned that "caution is indicated in applying presently available data on cellulose membranes due to the possibility that the properties of the membranes may be altered by absorption of plasma proteins".

Other investigators (BABB et al., 1968; GAYLOR et al., 1970) have reported significant decreases in the passage across membranes of small uncharged molecules such as urea when the system is changed from water/water to blood/dialysate. Moreover GAYLOR et al. (1970) show that there is a distinct haematocrit effect with the decrease in permeability becoming more pronounced as the haematocrit increases. In our experiments the overall diffusion coefficient $D$ of sodium in both systems appeared to be flow independent and can be considered to be a constant for any given combination of fluids and membrane. The accuracy of the determination of $D$ in a given experiment is limited largely by unavoidable reading errors. Most of the variability in $D$ values occurred between rather than within experiments and was probably due to a variation in stretching of the membranes. Stretching may lead to deformations in the membrane structure and therefore to alterations in permeability of the substances involved (CRAIG and KonigsBERG, 1961).

The performance of dialysers is usually expressed as dialysance, sometimes as clearance. These terms which are often used interchangeably, are identical only in non-flow models. This is discussed in detail in the previous investigation (STINSON and DE BOER, 1970). The equation for clearance which is valid only for the model described, i.e. recirculation of blood and counterflow single-passage dialysate, takes into account manageable variables. It indicates that increases of blood flow, dialysate flow, overall diffusion coefficient of the substance to be removed, membrane surface area and decreases of membrane thickness will increase the clearance and in addition, shows that there is no interaction between these variables. The flow dependency of the clearance of any diffusable substance appeared to be an asymptotic one as is demonstrated empirically by many investigators.

The present experiments have verified the theory. However, in vivo experiments have to be performed in order to examine the usefulness in haemodialysis procedures. It is anticipated that the theory has to be extended, because in vivo experiments deal with a three or more compartment system. This will form the basis for future experiments.

\section{REFERENCES}

Babb, A. L., Maurer, C. J., Fry, D. L., Popovich, R. P. and Ramos, C. P. (1968) Methods for the in vivo determination of membrane permeabilities and solute diffusivities. Trans. Am. Soc. Artif. int. Organs 14, 25-31.

DE BoER, J. and Stinson, R. H. (1972) Rationalization and Optimization of Hemodialysis Procedure-IV. Submitted for publication to Med. biol. Engng.

De Boer, J., Roukens, J., DuYfF, J. W. and Mandel, M. (1966) Rationalization and Optimization of Hemodialysis Procedure I. Acta physiol, pharmacol, Neerl. 14, 205-219.

Colton, C. K. (1967) A Review of the Development and Performance of Hemodialyzers. National Institutes of Health, Bethesda, Maryland.

Craig, L. C. and Konigsberg, W. J. (1961) Dialysis studies, III. Modification of pore size and shape in cellophane membranes. Phys. Chem. 65, 166-172.

Gaylor, J. D. S., MuIR, W. M. and Allen, W. T. (1970) Kinetics of solute transfer from whole blood in haemodialyser. Med. biol. Engng 8, 1-13.

LANGe, Y., LANGe, R. V. and Solomon, A. K. (1970) Cellular inhomogeneity in dog red cells as revealed by sodium flux. J. gen. Physiol. 56, 438-461.

LYMAN, D. J. (1963) Investigation of synthetic membranes for hemodialysis. Trans. Am. Soc. Artif. int. Organs 9, 92-96.

MACEY, R. I. and WoLF, A. V. (1960) Kinetics of ultrafiltration hemodialysis. Bull. Math. Biophys. 22, 217-226. 
Pappenheimer, J. R., Renkin, E. M. and Borrero, L. M. (1951) Filtration, diffusion and molecular seiving through peripheral capillary membranes. A contribution to the pore theory of capillary permeability. $\mathrm{Am}$. J. Physiol. 167, 13-46.

RENKIN, E. M. (1956) The relation between dialysance, membrane area, permeability and blood flow in the artificial kidney. Trans. Am. Soc. Artif. int. Organs 2, 102-105.

Skeggs, L. T., Leonards, J. R. and Heisler, C. R. (1949) Artificial Kidney. II. Construction and operation of an improved continuous dialyzer. Proc. Soc. exp. Biol. Med. 72, 539-543.
Stinson, R. H. and DE BOER, J. (1970) Rationalization and optimization of hemodialysis procedure II. Can. $J$. Physiol. Pharmacol. 48, 438-441.

SweEney, M. J. and Galletti, P. M. (1964) A practical point of reference for evaluation of mass transfer capacity of hemodialyzers. Trans. Am. Soc. Artif. int. Organs 10, 3-10.

Villegas, R., Barton, T. C. and Solomon, A. K. (1959) The entrance of water into beef and dog red cells. J. gen. Physiol. 42, 355-369.

Wilcox, C., Freeman, R. B., Maher, J. F. and SCHREINER, G. E. (1960) Comparison of physical properties and permeability of six cellulose membranes. Trans. Am. Soc. Artif. int. Organs 12, 44-52.

\section{LA RATIONALISATION ET LE MEILLEUR USAGE DU PROCEDE DE LA HEMODYALISE-III}

Sommaire-Pour les dialyseurs à contre-courant avec un seul passage, on a conçu une équation qui incorpore les rythmes d'écoulement dans les compartiments de sang et de dialysate, le volume de sang, le coefficient de diffusion globale de la substance impliquée et les propriétés géométriques de la membrane. Pour vérifier la théorie, on a étudié les effets de l'ècoulement dans les compartiments de sang et de dialysate, sur le transfert en masse du sodium à travers les membranes dans un dialyseur de Kiil dans des expériences in vitro, en utilisant des systèmes eau/eau et sang/dialysate. On a déterminé les propriétés géométriques des membranes et le coefficient de la diffusion globale du sodium. Le dernier a été moindre dans le système sang/ dialysate que dans le système eau/eau. L'efficacité de ce dialyseur a jété presentée comme un dégagement. La dépendance de l'écoulement du dégagement paraît être asymptotique, comme démontré empiriquement par des nombreux investigateurs. Des points expérimentaux positifs ont suivi les courbes théoriques et ont vérifié la théorie. La théorie doit être élargie pour concourir avec les expériences in vivo.

\section{RATIONALISIERUNG UND OPTIMISIERUNG VON HÄMODIALYSEVERFAHREN}

Zusammenfassung-Eine Gleichung für Einzeldurchgang-Gegenstrom Dialysatoren ist abgeleitet worden, die Strömungsgeschwindigkeiten im Blut und in Dialysierabschnitten, Blutvolumen, gesamten Diffusionskoeffizienten der enthaltenen Substanz und geometrische Membraneigenschaften vereinigt. Zur Bestätigung der Theorie wurden Wirkungen des Stroms in Blut und Dialysierabschnitten auf Massenübergang von Natrium durch die Membranen in einem Kiil Dialysator in Experimenten in vitro bei Verwendung von Wasser/Wasser und Blut/Dialysier Systemen untersucht. Es wurden die geometrischen Eigenschaften der Membranen und der Gesamtdiffusionskoeffizient von Natrium ermittelt. Letzterer war kleiner in dem Blut/Dialysier System als in dem Wasser/Wasser System. Die Leistungsfähigkeit dieses Dialysators wurde als Freimachung ausgedrückt. Die Abhängigkeit des Stromes von der Freimachung schien asymptotisch zu sein, wie auf empirische Weise von vielen Prüfern gezeigt worden ist. Wirkliche experimentelle Punkte folgten den theoretischen Kurven und bestätigten die Theorie. Die Theorie muss erweitert werden, um sich mit in vivo Experimenten zu befassen. 